\title{
CRATERS PRODUCED ON Al, Cu AND Au by Ar CLUSTER IMPACTS*
}

\author{
R. C. Birtcher1, J. Matsuo ${ }^{2}$, and I. Yamada 2 \\ ${ }^{1}$ Materials Science Division \\ Argonne National Laboratory \\ 9700 S. Cass Ave. \\ Argonne, IL 60439 \\ ${ }^{2}$ Ion Beam Engineering Experimental Laboratory \\ Kyoto University \\ Sakyo, Kyoto 606, Japan
}

\section{September 2000}

The submitfed manuscript has
been created by the University of
Chicago as Operator of Argonne
National Laboratory ("Argonne")
under Contract No. W-31-109
ENG-38 with the U.S. Department
of Energy. The U.S. Government
retains for itself, and others
acting on its behalf, a paid-up,
non exclusive, irrevocable
worldwide license in said article
to reproduce, prepare derivative
works, distribute copies to the
public, and perform publicly and
display publiciy, by or on behali
of the Government.

Submitted to the International Conference on Ion Beam Modification of Materials, CanelaRio Grande do Sul, Brazil, on September 3-8, 2000.

*Work supported by the U. S. Department of Energy, Office of Science, under Contract W-31-109-Eng-38. 


\section{DISCLAIMER}

This report was prepared as an account of work sponsored by an agency of the United States Government. Neither the United States Government nor any agency thereof, nor any of their employees, make any warranty, express or implied, or assumes any legal liability or responsibility for the accuracy, completeness, or usefulness of any information, apparatus, product, or process disclosed, or represents that its use would not infringe privately owned rights. Reference herein to any specific commercial product, process, or service by trade name, trademark, manufacturer, or otherwise does not necessarily constitute or imply its endorsement, recommendation, or favoring by the United States Government or any agency thereof. The views and opinions of authors expressed herein do not necessarily state or reflect those of the United States Government or any agency thereof. 


\section{DISCLAIMER}

\section{Portions of this document may be illegible in electronic image products. Images are produced from the best available original document.}




\title{
Craters Produced on $\mathrm{Al}, \mathrm{Cu}$ and $\mathrm{Au}$ by $\mathrm{Ar}$ cluster Impacts
}

\section{OSTI}

\author{
R. C. Birtcher\$, J. Matsuo ${ }^{¥}$ and I. Yamada
}

\$ Materials Science Division, Argonne National Laboratory, Argonne, IL. 60439, USA

$¥$ Ion Beam Engineering Experimental laboratory, Kyoto University Sakyo, Kyoto 606 Japan

\begin{abstract}
Transmission electron microscopy has been used to observe craters produced on $\mathrm{Al}, \dot{\mathrm{Cu}}$ and $\mathrm{Au}$ at room temperature by the impact of Ar clusters. Irradiations were made at normal incidence with Ar clusters of either 100 or 1000 atoms having an energy of $100 \mathrm{keV}$. The probability of a cluster to make a crater decreases with increasing target atomic mass or density. At a given total energy, the probability of a cluster to make a crater increases with increasing cluster size. This increase in cratering rate with decreasing energy per atom in the cluster occurs because of greater energy deposition near the specimen surface due to increased rate of energy loss by individual atoms in the cluster.
\end{abstract}

PACS: $\quad$ 61.35.BS, 68.55, 61.72.Ff

Keywords: cluster beam, impact, crater, metals, surface modification

Robert C. Birtcher

Materials Science Division

Argonne National Laboratory

9700 South Case Ave.

Argonne, IL 60439

USA

e-mail: birtcher@anl.gov

FAX: 630-252-4798

Phone: $\quad 630-252-4996$ 


\section{INTRODUCTION}

Energetic beams of clusters containing up to several thousand gas atoms have become available [1]. The results of bombardment with such cluster beams are of scientific and potentially technological importance in fields of thin film growth, shallow implantations, SIMS and surface processing. It is well known that the impact of atomic clusters causes major topographical changes [2] and enhanced sputtering [3]. In some cases, cluster impacts result in smoothing, but the most striking of these changes is the production of craters on specimen surfaces. Craters on graphite [4] have been produced by clusters of $\mathrm{C}, \mathrm{Ar}, \mathrm{N}, \mathrm{O}, \mathrm{Ga}, \mathrm{CsI}, \mathrm{Au}$ and Ta. Cluster irradiations have also produced craters on $\mathrm{Au}$ and sapphire [5]. Visible craters range in diameter from 1 to $5 \mathrm{~nm}$ in diameter and appear to be as deep as wide. In this work transmission electron microscopy has been used to examine the surfaces of $\mathrm{Al}$, $\mathrm{Cu}$ and $\mathrm{Au}$ after irradiation with $\mathrm{Ar}$ clusters of different sizes. Craters have been found in all cases. 


\section{EXPERIMENTAL}

Transmission electron microscopy specimens of $\mathrm{Al}, \mathrm{Cu}$ and $\mathrm{Au}$ were prepared by electrochemical jet thinning of well annealed, high purity disks to perforation at Argonne National Laboratory in the USA. The specimens were mounted in a stainless steal irradiation holder, and the assembly was sealed in a quartz tube filled with $1 \mathrm{~atm}$ of Ar and transported to Japan. After cluster-beam irradiation the specimen assembly was returned to Argonne National Laboratory where the specimens were removed and examined in a Hitachi H-9000 electron microscopy.

Ar cluster irradiations were performed at Kyoto University [1]. Cluster beams were produced by the adiabatic expansion of Ar at supersonic speed into high vacuum. The beam was collimated and then ionized by electron bombardment. Clusters were singly charged. After extraction, the cluster beam was accelerated to $100 \mathrm{keV}$. Cluster size was controlled by gas pressure in the source and electrostatic mass filtering. This results in a broad distribution of cluster sizes. Irradiations were made with cluster containing an average of either 100 or $1000 \mathrm{Ar}$ atoms. Specimens were irradiated at room temperature to doses of $210^{10}$ and $510^{10} \mathrm{Ar}$ clusters $/ \mathrm{cm}^{2}$. The cluster impacted the specimens at normal incidence. 


\section{RESULTS}

Transmission electron microscopy (TEM) examination of the specimens after cluster irradiation at room temperature revealed that cluster impacts produced craters on the three materials irradiated. Figure 1 shows images of craters on $\mathrm{Al}$ produced by $100 \mathrm{keV}$ clusters of 100 or $1000 \mathrm{Ar}$ atoms. This pair of micrographs is typical of craters produced on $\mathrm{Cu}$ or $\mathrm{Au}$ by Ar clusters as well as craters produced by single heavy ions on $\mathrm{Au}[6]$. Subsequent examinations show that the craters are stable a room temperature for periods longer than several months.

The number density of the craters produced by each irradiation on all three materials was determined from areas approximately ten times larger than shown in figure 1 . For the irradiation dose range studied, the number of craters scaled with the cluster dose indicating that the cratering rate by cluster impacts was independent of dose for all materials studied. A linear accumulation of craters followed by a steady state density under continuous irradiation was also observed during in situ, single ion irradiation of a variety of metals [6,7]. The in situ observations of single ion irradiations revealed that single ion impacts can annihilate craters, even if a new crater is not produced, resulting in a saturation of the crater density at high dose. A cluster cratering rate that is independent of dose indicates that subsequent cluster impacts did not significantly annihilate existing craters and that the crater density has not began to approach a saturation value. The linear rate of increase is determined by the cross section for a single impact to produce a crater, and the saturation value is determined by the ratio of the production cross section to the cross section for an impact to annihilate a crater. In order to remain in the linear domain and allow determination of the crater production rates during the current ex situ experiments, total cluster doses of less than $510^{10} \mathrm{~cm}^{-2}$ were used. In this case, only one or two percent of the surface was impacted by a cluster or covered by craters, and the 
probability that a crater was annihilated during any irradiation is estimated to be less than one percent.

Although the images of craters are similar for all the materials studied, cluster impacts more readily produce craters on a light, low $\mathrm{Z}$ material such as $\mathrm{Al}$ than on a dense, high $\mathrm{Z}$ material such as Au. Cratering rates, the number of craters per cluster impact, are plotted in figure 2. The uncertainty in the results is greatest for $\mathrm{Cu}$ because of 1 to $10 \mathrm{~nm}$ size surface irregularities on the as-prepared specimens. TEM observations can not provide accurate information on the depth of craters and the amount of material affected, but indications from STM observations of craters on Au by single ion impacts suggest that craters are slightly less deep than their radius.

\section{DISCUSSION}

For a given energy and cluster size, the cratering rate decreases as the target density and atomic mass increases. This is counter to what has been observed for single ion impacts where the cratering rate increases with target density [7]. The different behaviors are due to the different rates of energy loss and different efficiencies to deposit large amounts of energy into small volumes at the specimen surface. Ranges of both single ions and recoiling target atoms in low density, low $\mathrm{Z}$ materials are too long for the irradiation to achieve the required density of energy deposition in a dense displacement cascade. On the other hand, the individual lowenergy atoms in a cluster are unable to effectively penetrate dense, high $\mathrm{Z}$ materials. The result is that a single $100 \mathrm{keV}$ Ar ion is more effective at making a dense cascade in $\mathrm{Au}$ than $\mathrm{Al}$, while a $100 \mathrm{keV}$ Ar cluster with $1 \mathrm{keV} / \mathrm{Ar}$ is more effective on $\mathrm{Al}$ than $\mathrm{Au}$. 
For a given target material and acceleration voltage, larger clusters are more efficient at making craters than smaller clusters, and these craters tend to have larger sizes. As the cluster size is increased at a fixed acceleration voltage, more target atoms will be directly affect by a cluster impact. Thus the probability for an impact event to generate a structure that remains on the surface increases with cluster size. This may also be viewed in terms of the energy per Ar atom in a cluster, which decreases with increasing cluster size at constant acceleration voltage. As the energy per $\mathrm{Ar}$ atom in a cluster increases (decreasing cluster size), the cratering rate for the materials studied decreases. The decrease is greatest for lower density materials, and in the limit of a single ion, cratering is observed during in situ irradiation of Au but not $\mathrm{Al}$. Coupled to the production of craters on Au by single ion impacts is the ejection of Au nanoparticles with comparable sizes [6,8]. These nanoparticles make a significant contribution to the total sputtering yield.

Overall, these results indicate that craters are produced when an ion or cluster impact deposits a critical energy density that results in melting of a sufficiently large volume in the near surface region [7]. In most materials this requires between 1 and $2 \mathrm{eV}$ per atom. This requires either a dense cascade produced by either a recoil from a single ion impact, such as can occur in Au but not in Al, or a high impact-energy density from a cluster, such as can be achieved on $\mathrm{Al}$. 


\section{REFERENCES}

1 I. Yamada and ,J. Matsuo, Mat. Sci. in Semiconductor Processing 1, 27 (1998).

2 H. Kitani, N. Toyoda, J. Matsuo and I. Yamada, Nucl. Instr. And Meth. B $\underline{121}$, 489 (1997).

3 I. Yamada and J. Matsuo, Mat. Res. Soc. Symp. 396, 149, (1996).

4 T. Seki, T. Kaneko, D. Takeuchi, T. Aoki, J. Matsuo, Z. Insepov and I. Yamada, Nucl. Instr. And Meth. B 121, 498 (1997).

5 D. Takeuchi, K. Fukushima, J. Matsuo and I. Yamada, Nucl. Instr. And Meth. B 121, 493 (1997).

6 S. E. Donnelly and R. C. Birtcher, Phys. Rev. B1 56, 13599 (1997).

7 S. E. Donnelly and R. C. Birtcher, Phil. Mag. A. 79, 133 (1999).

8 R. C. Birtcher, S. E. Donnelly and S. Schlutig, to be published Phys. Rev. Lett.

\section{FIGURES}

Figure 1 TEM images of craters produced on $\mathrm{Al}$ by room temperature bombardment with clusters containing an average of $1000 \mathrm{Ar}$ atoms. Two different doses are shown: a, $2 \times 10^{10} \mathrm{Ar} / \mathrm{cm}^{2}$; and b, $5 \times 10^{10} \mathrm{Ar} / \mathrm{cm}^{2}$.

Figure 2 The number of craters produced per Ar cluster impact as a function of the number of Ar atoms in the cluster for $100 \mathrm{keV}$ irradiations. 


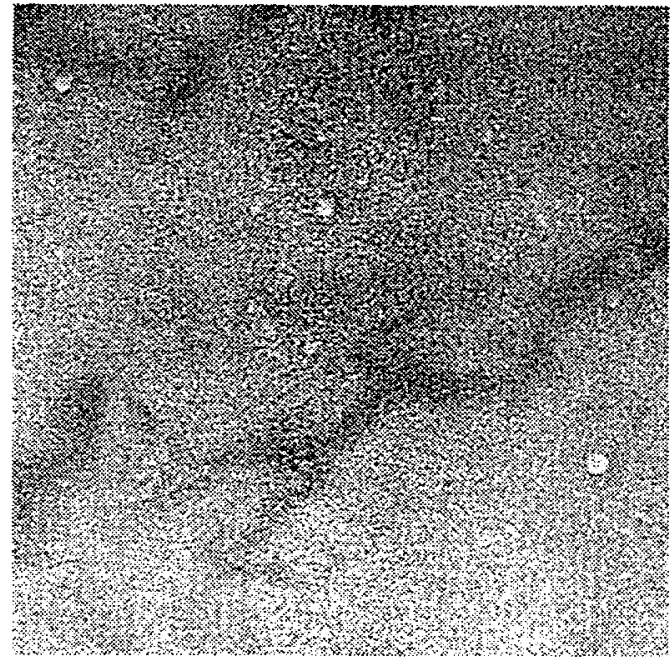

a

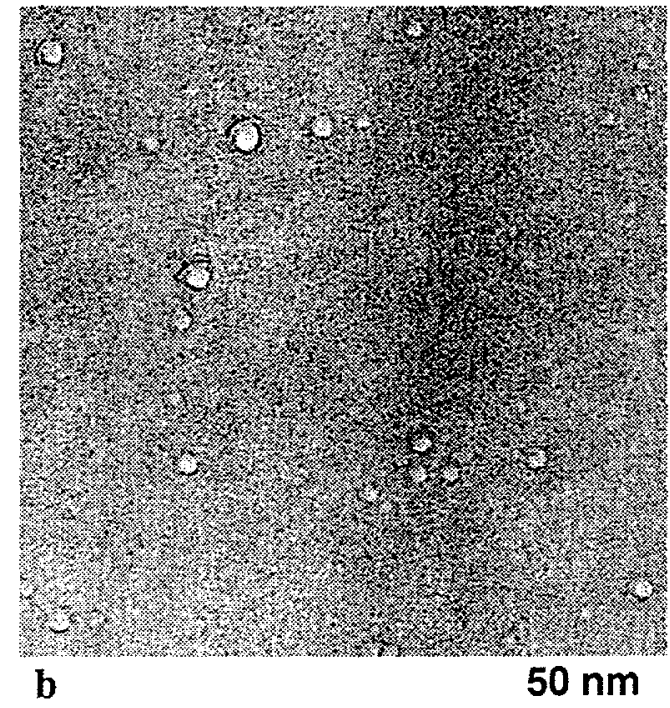

Figure 1

Birtcher et al. 


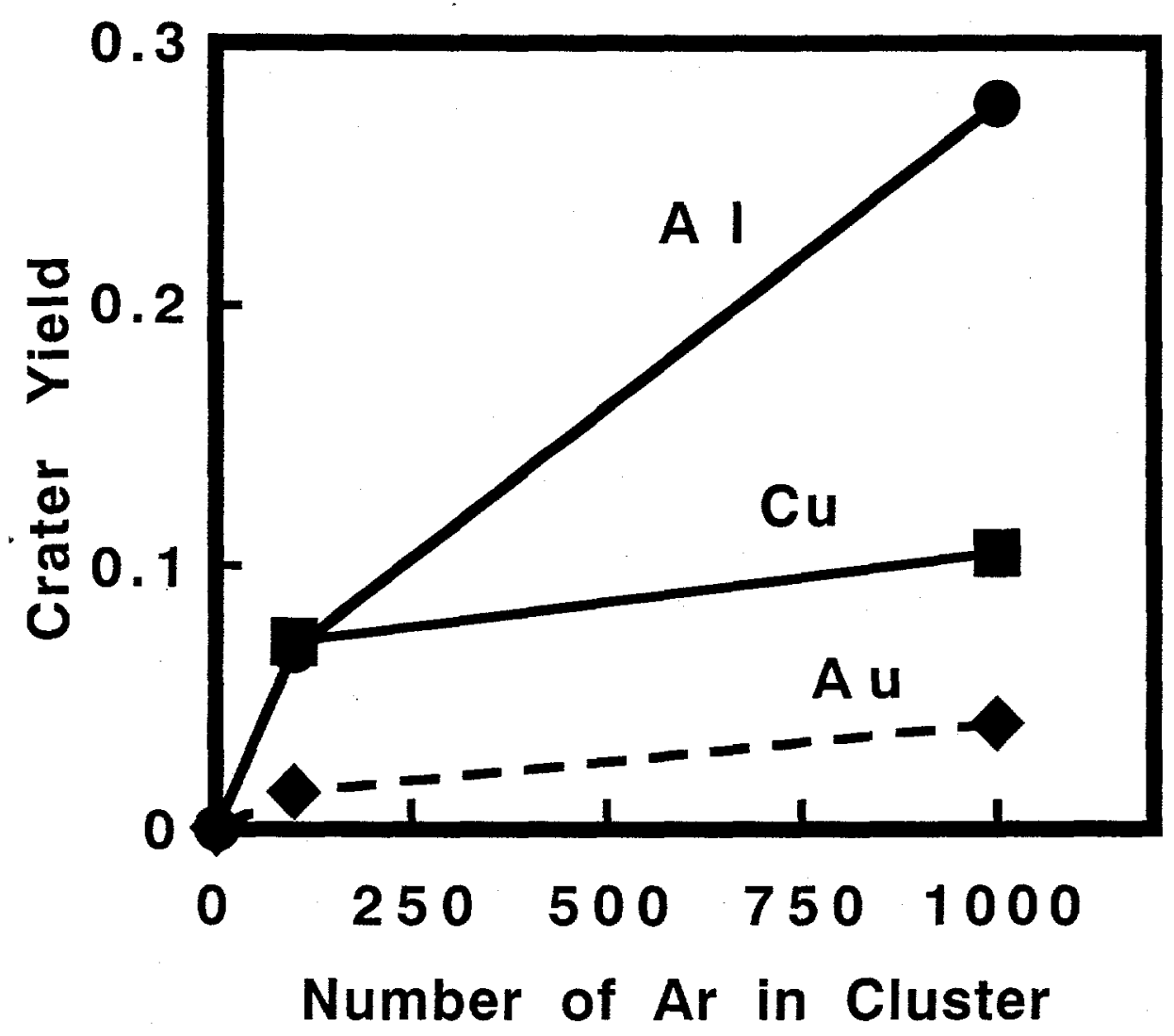

Figure 2 The number of craters produced per Ar cluster impact as a function of the number of Ar atoms in the cluster for $100 \mathrm{keV}$ irradiations. 